\title{
Dairy farmers with larger herd sizes adopt more precision dairy technologies
}

\author{
J. I. Gargiulo, ${ }^{*}$ C. R. Eastwood,† S. C. Garcia,ł and N. A. Lyons $\S^{1}$ \\ *Mastellone Hnos, General Rodriguez BA 1748, Argentina \\ †DairyNZ, Hamilton 3240, New Zealand \\ ¥Dairy Science Group, School of Life and Environmental Sciences, Faculty of Science, The University of Sydney, Camden NSW 2570, Australia \\ §Intensive Livestock Industries, NSW Department of Primary Industries, Elizabeth Macarthur Agricultural Institute, Menangle NSW 2568, Australia
}

\section{ABSTRACT}

An increase in the average herd size on Australian dairy farms has also increased the labor and animal management pressure on farmers, thus potentially encouraging the adoption of precision technologies for enhanced management control. A survey was undertaken in 2015 in Australia to identify the relationship between herd size, current precision technology adoption, and perception of the future of precision technologies. Additionally, differences between farmers and service providers in relation to perception of future precision technology adoption were also investigated. Responses from 199 dairy farmers, and 102 service providers, were collected between May and August 2015 via an anonymous Internet-based questionnaire. Of the 199 dairy farmer responses, $10.4 \%$ corresponded to farms that had fewer than 150 cows, $37.7 \%$ had 151 to 300 cows, $35.5 \%$ had 301 to 500 cows; $6.0 \%$ had 501 to 700 cows, and $10.4 \%$ had more than 701 cows. The results showed that farmers with more than 500 cows adopted between 2 and 5 times more specific precision technologies, such as automatic cup removers, automatic milk plant wash systems, electronic cow identification systems and herd management software, when compared with smaller farms. Only minor differences were detected in perception of the future of precision technologies between either herd size or farmers and service providers. In particular, service providers expected a higher adoption of automatic milking and walk over weighing systems than farmers. Currently, the adoption of precision technology has mostly been of the type that reduces labor needs; however, respondents indicated that by 2025 adoption of data capturing technology for monitoring farm system parameters would be increased.

Key words: automation, precision dairy farming, survey, technology investment

Received June 13, 2017.

Accepted January 21, 2018.

${ }^{1}$ Corresponding author: nicolas.lyons@dpi.nsw.gov.au

\section{INTRODUCTION}

Reductions in the number of dairy farms, together with an increase in the average herd size and milk production per herd, have been previously reported in most of the main dairy regions across the world (AHDB Dairy, 2016; DairyNZ, 2016; USDA, 2017). In Australia, dairy farm numbers declined by $60 \%$ between 1990 and 2015. During the same period, the average herd size has increased from 107 cows per farm to 272 (around 150\%; Dairy Australia, 2016). More than $90 \%$ of dairy farms in Australia are still family owned and operate with variable levels of external labor (Dairy Australia, 2015a,c). The availability of skilled labor, and the demands of animal management due to larger herd sizes, have been identified as 2 key variables that might limit future increases in production and profitability on Australian dairy farm systems (Dairy Australia, 2015b).

Farmers considering expanding their business need to ensure best practices in herd management, operations, finances, human resources, and strategic management (Hadley et al., 2002). As dairy operations continue to increase in size, monitoring and managing cows has become more challenging and complex and requires enhanced management ability (Edwards et al., 2015; Bewley, 2016). The use of automation and sensor systems, commonly termed precision technology, is increasingly providing farmers with the means to reduce labor requirements and to improve management of large herds (Bewley, 2010; Eastwood et al., 2012, 2016a). On one hand, there are certain technologies that offer the possibility of either reducing pressure on labor or improving labor efficiency, especially in larger herds. This includes technologies such as automation of cup removers, sorting gates, calf feeders, post milking disinfection and milk plant wash systems (Edwards et al., 2015). Additionally, there are other precision technologies that rely on data capture and are currently used to monitor parameters at an individual cow level to increase production efficiency and performance of dairy farms. This group includes technologies such as automatic estrus detection systems, inline milk meters, electronic cow identification systems and herd management software. 
However, these data capturing technologies have only been adopted on a small proportion of farms globally (Bewley, 2010; Rutten et al., 2013; Borchers and Bewley, 2015; Edwards et al., 2015).

Service providers in the dairy industry include people from the private and public sector such as agronomists, veterinarians, nutritionists, consultants, researchers, and farm equipment technicians. They represent an important part of the dairy farmers' network and are an important influence in decision making (Klerkx and Jansen, 2010; Eastwood et al., 2012; Murphy et al., 2013). Opportunities exist for service providers to integrate precision technologies into their businesses and in the interaction with farmers, for example by setting up customized reports around animal health or nutrition (Eastwood et al., 2016a,b).

Previous surveys conducted on dairy farms in different countries have investigated precision technology adoption (Watson, 2009; Khanal et al., 2010; Dharma et al., 2012; Borchers and Bewley, 2015; Edwards et al., 2015). However, in a global context of increasing farming scale, little is known about the influence of herd size on farmer decision-making concerning on-farm precision technology investment. In addition, few surveys have addressed the perception of service providers, despite recognizing that collectively they influence a large number of farmers (Eastwood et al., 2016b). To address this gap, we conducted a survey with the aim of understanding the relationship of herd size on adoption of technologies on Australian dairy farms, as well as investigating the perception of farmers and service providers toward future technology adoption. The findings would allow commercial companies, research, and dairy policy organizations to be much more effective in the development and support of new precision technologies.

\section{MATERIALS AND METHODS}

\section{Survey Design}

A multidisciplinary team including researchers, farmers and professional officers coordinated by the NSW Department of Primary Industries (New South Wales, Australia) designed the survey. It was distributed via the Internet using Google Forms (Google Inc., Mountain View, CA). The survey included up to 32 questions depending on each respondent's profile. The first section allowed a general understanding of participants' demographics (such as region, age, role in the industry, and type of operation). The second section focused on the current adoption of milking-, animal-, and feedingrelated technologies as well as the perception of the future adoption of precision technologies (Table 1). Technologies selected for inclusion in the questionnaire were based on experience of the authors, augmented by external consultation with members of the Australian precision dairy reference group (facilitated by Dairy Australia, the service body for the Australian dairy industry). Survey participants also had the possibility of adding other technologies that were not included in the original list. A pilot of the survey was conducted with 5 farmers to refine the 32 questions and logic flow.

\section{Data Collection}

Participation in the survey was voluntary and anonymous. Participants were recruited using a snowball method where the survey was initially distributed to industry contacts of the project team, who were then asked to distribute the survey to participants via their own networks (Bryman, 2015). A link to the survey was

Table 1. Questions and options included in the survey relating to current precision technology adoption and perception of future technology use on Australian dairy farms

Which of the following technologies do you have?

Automatic milking systems

Electronic cow identification systems

Inline milk meters

Automated mastitis detection tools

Automatic cup removers

Automatic milk plant wash system

Automatic post milking disinfection

Automatic sorting gates

Walk over weighing

Automatic estrus detection systems

Automatic in parlor feeding (in the shed)

Automatic calf feeders

Herd management software

Pasture measuring device

Other
Which of the following technologies do you expect will have an increased adoption in next 10 years? 
also included in an email sent to the AusDairyL list server (the largest national dairy email list in Australia, reaching around 700 farmers and service providers), industry representatives in the 8 Australian dairy regions, the major technology and milking equipment suppliers, as well as other industry contacts. Using this methodology increased the likelihood of many dairy farmers and service providers receiving the survey invitation.

Responses to the survey were collected between May and August 2015. A total of 301 participants, including farmers and farm staff $(\mathrm{n}=199)$ and service providers $(\mathrm{n}=102)$, across all 8 dairy regions of Australia responded to the survey (with responses representing between 8 and $21 \%$ of the total farmer population within a particular region). To analyze precision technology adoption according to herd size, only responses from farm owners and managers were used $(\mathrm{n}=183)$ because they were considered primary decision makers on technology investments. All responses $(\mathrm{n}=301)$ were used to analyze perceptions of future technology adoption according to industry role; the 2 roles defined in this study were farmers or service providers.

\section{Statistical Analyses}

In the current study, the outcomes of interest related to current precision technology adoption as well as perception of future precision technology adoption. The main explanatory variables were either herd size or industry role. Farms were stratified into 5 categories based on the peak milking herd size during the previous 12 mo based on the categories used in the Australian National Dairy Farm Survey 2015 (Dairy Australia, 2015c): $<150$ cows (small); 151 to 300 cows (medium); 301 to 500 cows (large); 501 to 700 cows (X-large); and $>701$ cows (XX-large). Industry roles were classified as either farmer or service provider. Data were analyzed using Generalized Linear Modeling in Genstat 18th edition (VSN International, Hemel Hempstead, UK). Parameter estimates were calculated using restricted maximum likelihood procedures. Significance was determined if $P<0.05$, and the difference between means was determined using least significant differences at $P$ $<0.05$.

\section{RESULTS}

\section{Farms' General Information}

Respondents managed a range of farm sizes, with $10.4 \%$ of farms classified as small ( $<150$ cows), $37.7 \%$ as medium (151 to 300 cows), $35.5 \%$ as large (301 to 500 cows), $6.0 \%$ as X-large (501 to 700 cows), and $10.4 \%$ as XX-large (>701 cows). Eighty-eight percent of respon- dents reported pastures (defined as grazed pasture and other forages for more than 9 mo of the year) as the main feed source, $8 \%$ grazed their herd for less than 9 mo but also had a partial mixed ration (hybrid), and $4 \%$ managed zero grazing where cows were housed and fed a TMR. Most farmers (75\%) used either split or year-round calving patterns, with the remainder using seasonal calving. The majority of the farms (70\%) had either a swing-over or double-up herringbone parlor, whereas $26 \%$ of them used a rotary parlor and $4 \%$ an automatic milking system. The proportion of farms with more than 500 cows (classified as X-large and XXlarge) using rotary parlor was $87 \%$, whereas for farms with fewer than 500 cows (classified as small, medium, and large) it was 20\%. Most of the facilities (72\%), regardless of herd size, were built more than $10 \mathrm{yr}$ ago, and $60 \%$ of the farms had their facilities last upgraded 5 or more years ago. Most farms $(78 \%)$ had up to 2 people involved in part or all of the milking process at any one milking session (including cups on, cups off, and fetching of cows), with the remainder having 3 or more. Farmers with automatic milking systems were not directly involved in the milking process, and therefore were excluded from answering this question.

\section{Service Providers' General Information}

Of the service providers, $42 \%$ worked predominantly in dairy farm management and consulting (in areas such as agronomy, animal health, breeding, nutrition, and milk quality), $19 \%$ in research education, $19 \%$ in extension, $10 \%$ in farm equipment (sales, service, or technical support), $5 \%$ in milk processing, and $5 \%$ in other sectors (such as insurance and finance-banking). In an average month, $35 \%$ of the service providers had contact with fewer than 10 dairy farms, $31 \%$ between 11 to 20 dairy farms, $28 \%$ with over 20 dairy farms, and $5 \%$ did not have regular contact with dairy farms (these were mainly researchers and people working in the education sector).

\section{Current Precision Technology Adoption}

In most cases, larger herd size was associated with greater adoption of precision technologies $(P<0.05$, Table 2). Farms with herds with more than 500 cows (classified as X-large and XX-large in the survey) had a significantly higher adoption of most precision technologies than farms with herds with fewer than 500 cows. In the case of inline milk meters, automatic cup removers and automatic calf feeders, farms with herds with more than 150 cows had a higher adoption than farms with herds with fewer than 150 cows. 
Table 2. Current adoption of precision technologies on Australian dairy farms according to herd size (mean \pm SE)

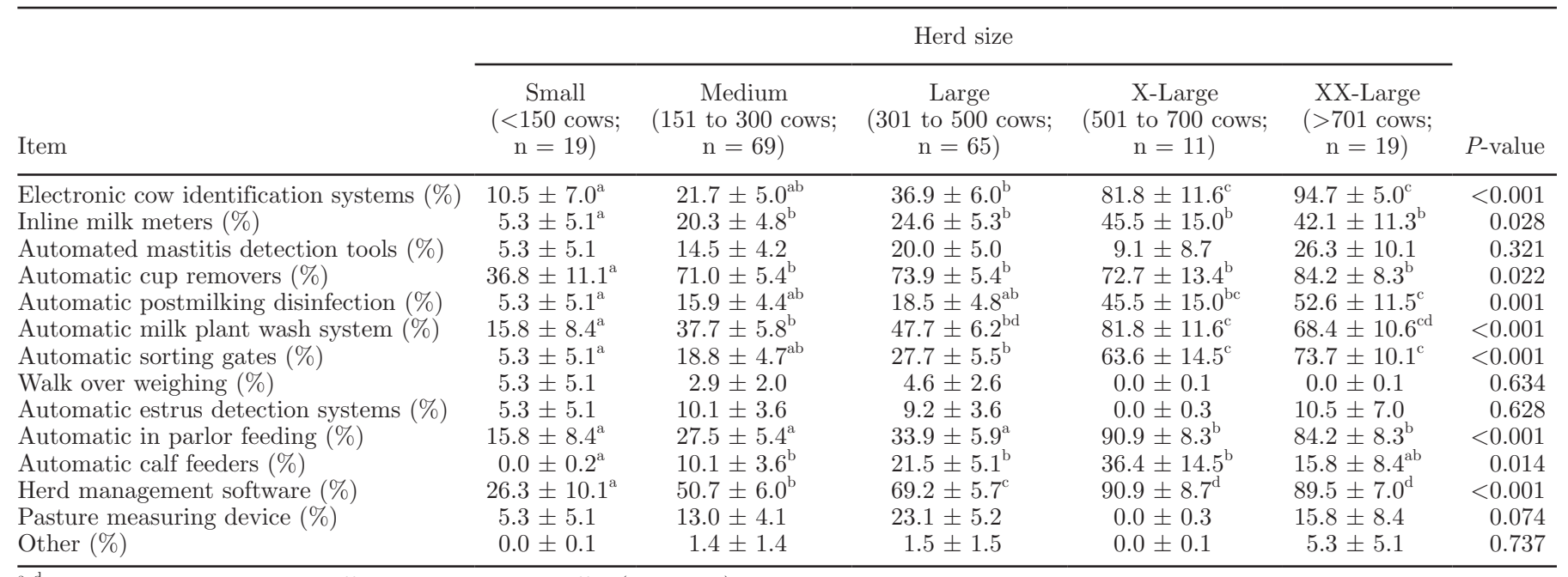

${ }^{\mathrm{a}-\mathrm{d}}$ Means within a row with different superscripts differ $(P<0.05)$.

No difference was observed among herd sizes in the adoption of automated mastitis detection tools, walk over weighing, automatic estrus detection systems, and pasture measuring devices. The adoption of these technologies was low, varying from 2.6 to $15.0 \%$ on average.

Regardless of herd size, automatic cup removers, herd management software, and automatic milk plant wash systems were the 3 most adopted precision technologies. Precision technologies mentioned by farmers and here categorized as "other" were rapid exit systems, soil moisture measuring devices, and computerized irrigation outlets.

\section{Perception of Future Precision Technology Adoption}

For the majority of the technologies, no significant differences were observed between herd sizes on farm- ers' perception of future precision technology adoption (Table 3). Expected increases in adoption of technologies ranged from $28.5 \%$ for walk over weighing to $79.8 \%$ for automatic estrus detection systems.

Only expected future adoption of inline milk meters had a significant difference between herd sizes (Table 3). In comparison to herd sizes of fewer than 300 cows, a significantly larger proportion of farmers with more than 700 cows considered that inline milk meters would have an increased adoption in the next $10 \mathrm{yr}$.

Overall, the 3 precision technologies that farmers expected would have the highest adoption in the next $10 \mathrm{yr}$ were automatic estrus detection systems (average $80 \%$ ), automatic sorting gates (average $74 \%$ ), and automated mastitis detection tools (average $63 \%$ ). Additional precision technologies that farmers identified as having potential increases in adoption and here catego-

Table 3. Percentage of farmer respondents who expected increased adoption of specific precision technologies on Australian dairy farms by 2025 , according to herd size (mean \pm SE)

\begin{tabular}{|c|c|c|c|c|c|c|}
\hline Item & \multicolumn{5}{|c|}{ Herd size } & $P$-value \\
\hline Automatic milking systems (\%) & $57.9 \pm 11.3$ & $55.1 \pm 6.0$ & $60.0 \pm 6.1$ & $81.8 \pm 11.6$ & $73.7 \pm 10.1$ & 0.321 \\
\hline Inline milk meters (\%) & $52.6 \pm 11.5^{\mathrm{ad}}$ & $42.0 \pm 5.9^{\mathrm{a}}$ & $64.6 \pm 5.9^{\text {bde }}$ & $63.6 \pm 14.5^{\mathrm{ae}}$ & $84.2 \pm 8.3^{\mathrm{ce}}$ & 0.006 \\
\hline Automated mastitis detection tools (\%) & $63.2 \pm 11.0$ & $59.4 \pm 5.9$ & $70.8 \pm 5.6$ & $45.5 \pm 15.0$ & $73.7 \pm 10.1$ & 0.365 \\
\hline Automatic estrus detection systems (\%) & $63.2 \pm 11.1$ & $73.9 \pm 5.3$ & $83.1 \pm 4.7$ & $100.0 \pm 0.3$ & $79.0 \pm 9.4$ & 0.054 \\
\hline Automatic calf feeders (\%) & $42.1 \pm 11.3$ & $43.5 \pm 6.0$ & $53.9 \pm 6.2$ & $45.5 \pm 15.0$ & $52.6 \pm 11.5$ & 0.752 \\
\hline Pasture measuring device (\%) & $36.8 \pm 11.1$ & $29.0 \pm 5.4$ & $36.9 \pm 6.0$ & $54.6 \pm 15.0$ & $52.6 \pm 11.5$ & 0.261 \\
\hline Other $(\%)$ & $0.0 \pm 0.1$ & $4.3 \pm 2.5$ & $1.5 \pm 1.5$ & $0.0 \pm 0.1$ & $5.3 \pm 5.1$ & 0.556 \\
\hline
\end{tabular}

\footnotetext{
${ }^{a-e}$ Means within a row with different superscripts differ $(P<0.05)$.
} 
Table 4. Percentage of farmer and service provider respondents who expected increased adoption of specific precision technologies on Australian dairy farms by 2025 (mean $\pm \mathrm{SE}$ )

\begin{tabular}{lccc}
\hline \multirow{2}{*}{ Item } & \multicolumn{2}{c}{ Industry role } \\
\cline { 2 - 3 } & $\begin{array}{c}\text { Farmer }^{1} \\
(\mathrm{n}=199)\end{array}$ & $\begin{array}{c}\text { Service provider } \\
(\mathrm{n}=102)\end{array}$ & $P$-value \\
\hline Automatic milking systems (\%) & $60.3 \pm 3.5^{\mathrm{a}}$ & $79.4 \pm 4.0^{\mathrm{b}}$ & $<0.001$ \\
Inline milk meters (\%) & $57.8 \pm 3.5$ & $54.9 \pm 4.9$ & 0.632 \\
Automated mastitis detection tools (\%) & $63.3 \pm 3.4$ & $67.6 \pm 4.6$ & 0.455 \\
Automatic sorting gates (\%) & $72.9 \pm 3.1$ & $76.5 \pm 4.2$ & 0.497 \\
Walk over weighing (\%) & $28.1 \pm 3.2^{\mathrm{a}}$ & $45.1 \pm 4.9^{\mathrm{b}}$ & 0.004 \\
Automatic estrus detection systems (\%) & $76.4 \pm 3.0$ & $81.4 \pm 3.9$ & 0.317 \\
Automatic calf feeders (\%) & $49.2 \pm 3.5$ & $58.8 \pm 4.9$ & 0.115 \\
Pasture measuring device (\%) & $38.2 \pm 3.4$ & $42.2 \pm 4.9$ & 0.506 \\
Other (\%) & $3.5 \pm 1.3$ & $3.9 \pm 1.9$ & 0.860 \\
\hline
\end{tabular}

${ }^{\mathrm{a}, \mathrm{b}}$ Means within a row with different superscripts differ $(P<0.05)$.

${ }^{1}$ Includes farm owner and farm staff.

rized as "other" were virtual fencing, robotic arms for rotaries, sensor-equipped drones, sensors for monitoring crops, and mobile data entry tools/apps.

For the majority of the technologies, no significant differences were detected between farmers and service providers on perception of precision technology adoption in the next $10 \mathrm{yr}$ (Table 4). The expected increased adoption ranged from $40.2 \%$ for pasture measuring devices to $78.9 \%$ for automatic estrus detection systems. However, a significantly greater proportion of service providers than farmers considered that automatic milking systems and walk over weighing would have an increased adoption in the next $10 \mathrm{yr}$ (Table 4).

Automatic estrus detection systems (average 79\%) and automatic sorting gates (average $75 \%$ ) were within the 3 precision technologies that a highest proportion of farmers and service providers expected to see an increased adoption in the next $10 \mathrm{yr}$. Precision technologies mentioned by service providers and here categorized as "other" were virtual fencing, inline pregnancy and disease detection, and sensors for monitoring crops.

\section{DISCUSSION}

The aim of this study was to identify the relationship between herd size and the current adoption of precision technologies, as well as farmers' and service providers' perception of future precision technology adoption. Overall, farmers with larger herds have adopted more precision technologies compared with those with smaller herd sizes, yet almost no difference was detected in perception of future adoption of precision technologies in relation to either herd size or industry role.

Although the current study only surveyed a small proportion of Australian dairy farmers, it represents the first study specifically designed to understand the difference in precision technology adoption, and per- ceptions of future technology adoption, according to herd size. Almost 200 Australian dairy farmers distributed geographically across all dairy regions, herd sizes, farming systems, and management types answered the survey, which is a higher number than a previous study that used a similar method (Borchers and Bewley, 2015). In comparison to the population of dairy farms in Australia (19\% small, 50\% medium, 19\% large, 6\% $\mathrm{X}$-large, and 5\% XX-large), the current study sampled a slightly higher proportion of large and XX-large farms (Dairy Australia, 2015c). The method (online based) and the voluntary nature of the survey could have affected the results. It is possible that given that the survey was only available online and was voluntary, respondent farmers might have been those more interested, more informed, more likely to adopt precision technologies, or a combination of these.

The greater current adoption of precision technologies on larger dairy farms, in comparison to smaller farms, might reflect farmers' attempts to address labor issues (availability, cost, skill level, and efficiency) as well as ensuring routines and protocols to monitor and manage larger scales of operation (Eastwood et al., 2016a). A similar situation was reported by Edwards et al. (2015) who found that $80 \%$ of New Zealand farmers operating with rotary parlors (operating herd sizes on average twice that of farmers using herringbone parlors) either had, or wanted, labor-saving technologies such as automatic cup removers, automatic post milking disinfection, automatic sorting gates, and automatic vat wash. Previous studies conducted in Australia showed that the proportion of farms with herringbone (double up and swing over) and rotary parlors was 81 and $19 \%$, respectively (Watson, 2009). The same author reported that the adoption of automatic cup removers had increased from $28 \%$ in 2004 to $40 \%$ in 2009, with similar adoption in both types of sheds. According to 
our study, the adoption of automatic cup removers in Australia was approximately $66 \%$ in 2015, again with no apparent differences between herringbones and rotaries (data not shown). Automatic cup removers are a very well-known and accepted technology that helps to improve milking consistency and increase labor efficiency (cows per labor unit; Tarrant and Armstrong, 2012). It also helps to reduce the incidence of overmilking, maintaining teat condition and milk quality (Rasmussen, 1999; Jago et al., 2010). These reasons and the fact that it is a relatively inexpensive and easy technology to use could explain the high level of adoption found throughout all farm sizes.

The difference in adoption of automatic in parlor feeding according to herd size might be explained by a greater proportion of larger farms having rotary parlors, in which automatic feeding systems are easier and cheaper to install. In the current study, data indicate that $80 \%$ of rotaries and $20 \%$ of herringbones had in-parlor feeding systems. These results are similar to those obtained by Edwards et al. (2015) in New Zealand, where $63 \%$ of rotaries (average herd size 659 cows) and $23 \%$ of herringbones (average herd size 314 cows) adopted this precision technology. In a survey carried out by Dharma et al. (2012), it was reported that in the period between 1991 to 1992 and 2010 to 2011, Australian dairy farms increased the level of concentrates, grain, or by-products from an average of 0.7 to $1.7 \mathrm{t} /$ cow per year. Considering that $96 \%$ of Australian dairy farms feed some level of grain/concentrate in bail (Dairy Australia, 2015d), automating this task could represent an improvement in labor efficiency during milking.

The automation of the milk plant wash system reduces labor requirements but also provides consistency of routines and operation (chemical dosing, water volume and temperature, and washing times; Reinemann et al., 2003), as well as minimizing health and safety issues associated with handling strong chemicals and hot water. In 2009, Watson (2009) reported that automatic plant wash systems appeared to be gaining popularity among Australian farmers and that adoption was higher for rotary $(54 \%)$ than for herringbone parlors $(19 \%)$. A similar situation was reported in the current study, with $62 \%$ of rotary and only $36 \%$ of herringbone parlors having this technology.

The adoption of sensors and more sophisticated precision technologies is facilitated by the incorporation of electronic cow identification systems (including both tag and reader) and computers, both of which enable the possibility of linking data or managing individual cow records. In Australia, the utilization of electronic radio frequency identification tags was introduced in 1999 and is currently mandatory for dairy farmers that intend to move animals between properties (NLIS, 2017). In this study adoption was low on small farms (around 10\%) and much higher on farms with more than 500 cows (around 88\%). Although there could be a proportion of farmers that do not move cattle off their property, it is more likely that some farmers do not have or use an antenna to read the tags for management purposes and therefore did not select the technology. In this survey, the majority of the X-large and XX-large farmers using electronic cow identification systems also used automatic sorting gates (70\%), which is in line with previous results reported by Watson (2009). Watson (2009) also stated that electronic cow identification systems had grown from 13 to $19 \%$ between 2004 and 2009. According to the results of the current study, around $30 \%$ of the farms in Australia had electronic cow identification systems in 2015 .

Several animal or feed monitoring technologies had similar adoption levels regardless of herd size. The fact that certain precision technologies are either only recently available to farmers, less known, not proven to work in particular conditions (for example, grazing systems), more expensive, or farmers do not know how to use them, could explain the lower or similar adoption between herd sizes (Borchers and Bewley, 2015). For example, walk over weighing systems provide detailed information about BW patterns and changes that can be used (together with other sensors) for some nutrition, reproduction, and health management decisions within a dairy (Maltz, 2015). Furthermore, they could also be used for monitoring heifers, as previously shown for beef cattle under grazing conditions (Gonzalez et al., 2014). Although no difference was present between herd sizes in current and expected future adoption of this technology, a greater proportion of service providers expected this technology to have an increased adoption within the next 10 yr. These differences might be explained by the lack of clear understanding on how to use such information or the difficulty to measure benefits at a farm level (Eastwood et al., 2016a; Dela Rue and Eastwood, 2017). It is possible that service providers have either the expertise or time to extract value from this type of data (Eastwood et al., 2016b). The same might be true for pasture measuring devices. Measuring pasture mass is difficult and time consuming, and therefore most farmers do not do it systematically (García and Fulkerson, 2005). Regular and systematic measurement of pasture could potentially not only increase average pasture utilization, but also milk production and profitability by feeding supplements in relation to pasture availability (Earle and McGowan, 1979; Fulkerson et al., 2005; French et al., 2015).

Despite current low adoption of automatic milking systems in Australia (around 40 farms by mid-2017), 
the technology was ranked among the top 5 for expected adoption in the next $10 \mathrm{yr}$, potentially because it not only addresses labor issues but also allows monitoring and management of several parameters at an individual cow level (Jacobs and Siegford, 2012; Lyons et al., 2014). However, the lower proportion of farmers than service providers (60.3 vs. $79.4 \%$, respectively) expecting an increased adoption in this technology might be explained by a higher proportion of service providers having mentioned that they had visited a farm operating with automatic milking systems (92\% of service providers vs. $75 \%$ of farmers, data not shown). Additionally, the higher capital cost related to commissioning automatic milking systems, together with variable on-farm system performance (Lyons and Kerrisk, 2017), might have been factors partly explaining the observed greater perceived risk for farmers (who actually have to invest in the technology) than for service providers. However, this difference in expected adoption of automatic milking systems between farmers and service providers by 2025 cannot be totally explained from these data and should be further investigated.

If farmers and service providers' perceptions of future precision technology adoption are achieved, we should expect improvements across the farm system. The use of automatic estrus detection systems can improve reproduction results and milk production (Stevenson, 2001), whereas inline milk meters and mastitis detection tools could enable earlier detection of diseases (García and Fulkerson, 2005; Kamphuis et al., 2016). To realize these opportunities, research is needed to adapt such technologies to a range of production systems (grazing versus indoor for example) as well as quantifying the monetary and nonmonetary benefits, which are not always clear for farmers (Jago et al., 2013). It is also important to realize that some barriers, such as lack of infrastructure (connectivity) or skills (computer knowledge or management and integration of data), might slow down the adoption of some precision technologies (Jago et al., 2013; Eastwood et al., 2017).

Although the findings in this study give a general understanding of current and potential future adoption of technology, they should be the base for further indepth surveys conducted in a larger sample size. That information would then help design education, training, and service programs to support dairy farmers.

\section{CONCLUSIONS}

Farmers with larger herds have adopted more precision technologies, such as electronic cow identification systems, automatic cup removers, automatic milk plant wash system, automatic in-parlor feeding, and herd management software when compared with farmers operating smaller sized herds. Results from the current study indicated that most of the precision technology currently installed on-farm is of the type that addresses labor issues, probably associated with larger herd sizes. Almost no difference was detected in respondents' perception of future precision technology adoption in relation to either herd size or industry role. Adoption of some of the precision technologies is still low, particularly for farms with fewer than 500 cows. The use of new technologies presents an opportunity to improve farm productivity and address future on-farm challenges related to environmental, animal care, and socio-ethical issues. However, greater clarity is needed to ascertain farm system-level benefits (monetary and nonmonetary) associated with the use of some precision technologies, to minimize investment uncertainty for farmers and to guide technology development.

\section{ACKNOWLEDGMENTS}

The authors thank the farmers and service providers who took part in the survey, as well as the industry representatives involved with designing, piloting, and distributing the survey. The study was funded by the NSW Department of Primary Industries.

\section{REFERENCES}

AHDB Dairy. 2016. Dairy Statistics: An Insider's Guide 2016. Accessed May 7, 2017. https://dairy.ahdb.org.uk/resources-library/ market-information/dairy-statistics/dairy-statistics-an-insiders -guide-2016/\#.WQ5gmk_fPIU.

Bewley, J. 2010. Precision dairy farming: advanced analysis solutions for future profitability. Pages $2-5$ in Proc. First North American Conference on Precision Dairy Management, Toronto, Canada.

Bewley, J. 2016. Opportunities for monitoring and improving animal welfare using precision dairy monitoring technologies. J. Anim. Sci. 94(Supplement2):11.

Borchers, M. R., and J. M. Bewley. 2015. An assessment of producer precision dairy farming technology use, prepurchase considerations, and usefulness. J. Dairy Sci. 98:4198-4205. https://doi .org/10.3168/jds.2014-8963.

Bryman, A. 2015. Social Research Methods. Oxford University Press, Oxford, UK.

Dairy Australia. 2015a. Investment and the Australian dairy industry: A guide for farmers and investors. Accessed Feb. 13, 2018. https://www.dairyaustralia.com.au/-/media/dairyaustralia/ documents / about-dairy-australia/key-publications / 0538 -investment-and-australian-dairy-industry20151218.ashx?la=en\& hash=4B914030D258C063859586DB746602139B8E6A1D.

Dairy Australia. 2015b. Sustainable farm profitability 2015. Accessed Feb. 13, 2018. https://www.dairyaustralia.com.au/ - / media/dairyaustralia/documents/farm/farm-business -management/farm-systems/sustainability-farm-profitability -project/2015-farm-profitability-report.ashx?la =en\&hash = 2E7DB7989693D345EFD2721B0EB6B99F03525E51.

Dairy Australia. 2015c. Dairy situation and outlook June 2015. Accessed Feb. 13, 2018. https://www.dairyaustralia.com.au/-/media/ dairyaustralia/documents/industry/industry-resources/dairy -situation-and-outlook/201506--situation-and-outlook.ashx?la=en \&hash $=$ CCE386066A83FE7F2DCB7C22B2DDA02F7957B3F4. 
Dairy Australia. 2015d. Feeding practices on Australian dairy farms, 2008-2009. Accessed Feb. 13, 2017. https://www.dairyaustralia .com.au/-/media/dairyaustralia/documents/farm/pasture -management/feed-management/feed-markets/dairy-feeding -update--briefing-notes.ashx.

Dairy Australia. 2016. Australian Dairy Industry In Focus 2016. Accessed Feb. 13, 2018. https://www.dairyaustralia .com.au/-/media/dairyaustralia/documents/about-dairy -australia/key-publications /2016-in-focus.ashx?la=en\&hash= 663613D9E790F02D90D825E6C842C31BCB3F40D0.

DairyNZ. 2016. New Zealand Dairy Statistics 2015-16. Accessed May 7, 2017. https://www.dairynz.co.nz/media/5416078/nz-dairy -statistics-2015-16.pdf.

Dela Rue, B. T., and C. R. Eastwood. 2017. Individualised feeding of concentrate supplement in pasture-based dairy systems: Practices and perceptions of New Zealand dairy farmers and their advisors. Anim. Prod. Sci. https://doi.org/10.1071/an16471.

Dharma, S., W. Shafron, and M. Oliver. 2012. Australian Dairy: Farm Technology and Management Practices, 2010-11. Australian Bureau of Agricultural and Resource Economics and Sciences, Canberra, Australia

Earle, D., and A. McGowan. 1979. Evaluation and calibration of an automated rising plate meter for estimating dry matter yield of pasture. Anim. Prod. Sci. 19:337-343.

Eastwood, C., D. Chapman, and M. Paine. 2012. Networks of practice for co-construction of agricultural decision support systems: Case studies of precision dairy farms in Australia. Agric. Syst. 108:10-18.

Eastwood, C., J. Jago, J. Edwards, and J. Burke. 2016a. Getting the most out of advanced farm management technologies: Roles of technology suppliers and dairy industry organisations in supporting precision dairy farmers. Anim. Prod. Sci. 56:1752-1760.

Eastwood, C., L. Klerkx, and R. Nettle. 2017. Dynamics and distribution of public and private research and extension roles for technological innovation and diffusion: Case studies of the implementation and adaptation of precision farming technologies. J. Rural Stud. 49:1-12.

Eastwood, C. R., S. Chaplin, B. Dela Rue, N. A. Lyons, and D. Gray. 2016b. Understanding the roles of farm advisors in precision dairy farming. Pages 421-426 in Proc. International Precision Dairy Farming Conference. Wageningen Academic Publishers, Leeuwarden, the Netherlands.

Edwards, J. P., B. T. Dela Rue, and J. G. Jago. 2015. Evaluating rates of technology adoption and milking practices on New Zealand dairy farms. Anim. Prod. Sci. 55:702. https://doi.org/10.1071/ an14065.

French, P., B. O'Brien, and L. Shalloo. 2015. Development and adoption of new technologies to increase the efficiency and sustainability of pasture-based systems. Anim. Prod. Sci. 55:931 https://doi .org/10.1071/an14896.

Fulkerson, W., K. McKean, K. Nandra, and I. Barchia. 2005. Benefits of accurately allocating feed on a daily basis to dairy cows grazing pasture. Anim. Prod. Sci. 45:331-336.

García, S. C., and W. J. Fulkerson. 2005. Opportunities for future Australian dairy systems: A review. Aust. J. Exp. Agric. 45:1041. https://doi.org/10.1071/ea04143.

Gonzalez, L. A., G. Bishop-Hurley, D. Henry, and E. Charmley. 2014. Wireless sensor networks to study, monitor and manage cattle in grazing systems. Anim. Prod. Sci. 54:1687. https://doi.org/10 $.1071 / a n 14368$.

Hadley, G. L., S. Harsh, and C. Wolf. 2002. Managerial and financial implications of major dairy farm expansions in Michigan and Wisconsin. J. Dairy Sci. 85:2053-2064.
Jacobs, J. A., and J. M. Siegford. 2012. Invited review: The impact of automatic milking systems on dairy cow management, behavior, health, and welfare. J. Dairy Sci. 95:2227-2247. https://doi.org/ 10.3168/jds.2011-4943.

Jago, J., C. Eastwood, K. Kerrisk, and I. Yule. 2013. Precision dairy farming in Australasia: Adoption, risks and opportunities. Anim. Prod. Sci. 53:907-916. https://doi.org/10.1071/an12330.

Jago, J. G., J. L. Burke, and J. H. Williamson. 2010. Effect of automatic cluster remover settings on production, udder health, and milking duration. J. Dairy Sci. 93:2541-2549. https://doi.org/10 $.3168 /$ jds.2009-2949.

Kamphuis, C., B. T. Dela Rue, and C. R. Eastwood. 2016. Field validation of protocols developed to evaluate in-line mastitis detection systems. J. Dairy Sci. 99:1619-1631. https://doi.org/10.3168/jds 2015-10253.

Khanal, A. R., J. Gillespie, and J. MacDonald. 2010. Adoption of technology, management practices, and production systems in US milk production. J. Dairy Sci. 93:6012-6022. https://doi.org/10 $.3168 /$ jds.2010-3425.

Klerkx, L. and J. Jansen. 2010. Building knowledge systems for sustainable agriculture: Supporting private advisors to adequately address sustainable farm management in regular service contacts. Int. J. Agric. Sustain. 8:148-163.

Lyons, N., K. Kerrisk, and S. Garcia. 2014. Milking frequency management in pasture-based automatic milking systems: A review. Livest. Sci. 159:102-116.

Lyons, N. A., and K. L. Kerrisk. 2017. Current and potential system performance on commercial automatic milking farms. Anim. Prod. Sci. 57:1550-1556.

Maltz, E. 2015. Advanced technologies to support precision dairy farming. Pages 7-20 in The Dairy Research Foundation's 2015 Symposium. Vol. 20. Faculty of Veterinary Science, The University of Sydney, Australia.

Murphy, C., R. Nettle, and M. Paine. 2013. The evolving extension environment: Implications for dairy scientists. Anim. Prod. Sci. 53:917-923.

NLIS. 2017. National Livestock Identification System Information. Accessed Mar. 28, 2017. https://www.nlis.com.au/NLIS -Information/.

Rasmussen, M. D. 1999. Benefits from early removal of the milking unit. Pages 55-61 in Proc. Br. Conf. on Mastitis, Stoneleigh, UK.

Reinemann, D. J., G. Wolters, P. Billon, O. Lind, and M. D. Rasmussen. 2003. Review of practices for cleaning and sanitation of milking machines. Bull. Int. Dairy Fed. 381:3-18.

Rutten, C. J., A. G. J. Velthuis, W. Steeneveld, and H. Hogeveen. 2013. Invited review: Sensors to support health management on dairy farms. J. Dairy Sci. 96:1928-1952. https://doi.org/10.3168/ jds.2012-6107.

Stevenson, J. S. 2001. Reproductive management of dairy cows in high milk-producing herds. J. Dairy Sci. 84:E128-E143.

Tarrant, K. A., and D. P. Armstrong. 2012. An economic evaluation of automatic cluster removers as a labour saving device for dairy farm businesses. AFBM J. 9:43.

USDA. 2017. National Agricultural Statistics Service. Accessed May 7, 2017. https://www.nass.usda.gov/Charts_and_Maps/Milk _Production_and_Milk_Cows/.

Watson, P. 2009. CowTime tracking survey 2009. Report completed for the Department of Primary Industries, Down to Earth Research, Frankston South, Australia. 